\title{
Inhaltsverzeichnis
}

Gabriele B. Clemens und Hans-Jürgen Lüsebrink

Einleitung

Politische Spannungsfelder - Enjeux politiques

Jean El Gammal

Le personnel et les élites politiques dans les grandes villes d'Europe

et des Etats-Unis à l'époque contemporaine

Rainer Hudemann

Transferstrukturen in Urbanisierungsprozessen. Versuch einer Typologie

Laura Mougel

Les principaux lieux d'éducation populaire dans les villes du Nord et de l'Est de la France. Instruction, intégration et émancipation de la classe ouvrière (fin $\mathrm{XIX}^{\mathrm{e}}$ - début $\mathrm{XX}^{\mathrm{e}}$ siècle)

Damien Tomasi

La Vitrine de la Patrie face au Reich. Les militants républicains et les militants du mouvement ouvrier dans l'espace public

à Nancy (1880-1914)

Ulrike Ernst

Die ,sozialistische Stadt' als Ausdruck politischer Repräsentation.

Idee und Realität der Nutzung öffentlichen Raums im Sozialismus

Daniel Makonnen

Berlin au cœur des migrations internationales.

Métropole ouverte, espaces urbains contrôlés 
Soziale Identitäten und Inszenierungen Identités et appropriations sociales

Gabriele B. Clemens

Städtische Kunstsammler und mäzenatisches Handeln.

Französisch-deutscher Kulturtransfer im 19. Jahrhundert

Aurore Arnaud

Les réseaux identitaires à Strasbourg. Germanisation, modernisation et frontières

Anita Schlögl

Remapping Mozart - Celebrating Authenticity. Festivals

und die Inszenierung von Authentizität in urbanen Räumen

Laure Gravier

Berlin, les nouveaux territoires de l'art

Anna Richter

Die Politik der culture-led urban regeneration am Beispiel

Liverpool, Kulturhauptstadt Europas 2008

Sébastien Rival

Georg Simmel et Robert Ezra Park. De Berlin à

Chicago, l'individu face à la ville

Aurélie Delage

In/out. Marginalité sociale et centralité spatiale. Les SDF en

gare de Pennsylvania Station (New York City, NY), étude de cas

Kulturen und Repräsentationen - Cultures et représentations

Estelle Weber

Présences féminines dans l'espace urbain à Metz au XVII ${ }^{\mathrm{e}}$ siècle

Ines Heisig

„Kinder, die unter Steinen aufwachsen“. Die Kinderdarstellung der

Neuen Sachlichkeit im Kontext der Großstadt der Weimarer Republik 
Daniel Reupke

Städtebau im Grenzraum. Die städtebauliche Entwicklung von

Luxemburg, Metz, Saarbrücken und Trier im 19. Jahrhundert - ein Vergleich

Sabine Steidle

Kinoarchitektur als Chiffre für großstädtisches Leben

und Modernität in der Weimarer Republik

Laura Frahm

Modernität und Wandel. Transformationen des urbanen Raums in Jonas (1957)

Aliénor Didier

Handlungsorte transatlantisch. Die filmische Repräsentation

der Städte Las Vegas, Paris und Berlin im CSI-Format

Birte Thomas

Die métro als urbaner Mythos in Kriminalromanen des 20. Jahrhunderts

Sarah Neelsen

Der Moderne auf der Spur. Mit Walter Benjamin durch die Pariser Passagen

\section{Laetitia Faivre}

Décrire une ville: „Heidelberg par ses mots“. Esquisse d'une analyse

lexicale et discursive de l'espace urbain

Jean El Gammal

Postface

Anhang

Zusammenfassungen (dt.)

Résumés (frz.)

Autorenverzeichnis

Bildnachweis 
